\title{
A New Comprehensive Evaluation System for Thermo-Tolerance in Tomato at Different Growth Stage
}

\author{
Mintao Sun, Fangling Jiang, Chuan Zhang, Meng Shen and Zhen Wu \\ Key Laboratory of Horticultural Plant Biology and Germplasm Innovation in East China, Ministry of Agriculture, College of \\ Horticulture, Nanjing Agricultural University, Nanjing 210095, China
}

\begin{abstract}
With global warming, heat stress is becoming a more frequent event and a major limiting factor for crop production. The evaluation of thermo-tolerance is essential for the cultivators to obtain the heat resistant genotypes and breeders to improve the thermo-tolerance of plants. Therefore, it is very important to perfect the existing evaluation system for thermo-tolerance. In this study, 30 tomato genotypes were treated with heat stress at germination, seedling and flowering stages. Each index was different and diverse in different tomato genotypes by doing variability analysis, difference analysis and Student's $t$ test. Before principal component analysis (PCA), a positive treatment for the negative and moderation indexes was performed. After correlation analysis, the authors performed PCA (including dimensionality reduction (DR), no dimensionality reduction (NDR) and optimal index (OI)), combining with subordinate function (SF), weight and cluster analysis. No matter at germination or seedling stage, the members of the groups were basically identical for DR, NDR and OI. Then 10 tomato genotypes were chosen from 30 randomly for verification. Compared all the evaluation systems, OI was the simplest and also could get as credible results as other methods. Therefore, in this study, OI could be adopted and improve the efficiency during the evaluation. At germination stage, germination power (GP) can accurately evaluate the thermo-tolerance, and at seedling stage, it was fresh weight (FW), internode length (IL) and dry matter percentage of seedling (DMP). Finally, all the indexes in the three stages were applied correlation analysis. Seedling stage showed significant positive correlation with flowering stage. In conclusion, this work improves the current system and set up a new comprehensive evaluation method named OI, which also improves the efficiency, guarantees reliability in screening thermo-tolerance of tomato for cultivators and expedites the process of breeding for resistance.
\end{abstract}

Key words: Tomato, thermo-tolerance, principal component analysis, subordinate function, cluster analysis, comprehensive evaluation.

\begin{tabular}{|c|c|c|c|}
\hline & \multirow[t]{3}{*}{ GI: } & \multirow{3}{*}{$\begin{array}{l}\text { Germination index; } \\
\text { Germination stage } D \text { value; } \\
\text { Seedling stage } D \text { value; }\end{array}$} \\
\hline \multicolumn{2}{|c|}{ Abbreviations } & & \\
\hline \multicolumn{2}{|c|}{ PCA: $\quad$ Principal component analysis; } & & \\
\hline \multirow{3}{*}{$\begin{array}{l}\text { DR: } \\
\text { NDR: } \\
\text { OI: }\end{array}$} & $\begin{array}{l}\text { Principal component analysis; } \\
\text { Dimensionality reduction; }\end{array}$ & GOID: & Germination optimal index $D$ value; \\
\hline & & SOID: & Seedling optimal indexes $D$ value. \\
\hline & $\begin{array}{l}\text { eviations } \\
\text { Principal component analysis; } \\
\text { Dimensionality reduction; } \\
\text { No dimensionality reduction; } \\
\text { Optimal index; }\end{array}$ & & \\
\hline SF: & $\begin{array}{l}\text { Principal component analysis; } \\
\text { Dimensionality reduction; } \\
\text { No dimensionality reduction; } \\
\text { Optimal index; }\end{array}$ & \multicolumn{2}{|c|}{ 1. Introduction } \\
\hline \multirow{2}{*}{$\begin{array}{l}\text { FW: } \\
\text { DW: }\end{array}$} & Fresh weight; & \multirow{2}{*}{\multicolumn{2}{|c|}{ Tomato (Solanum lycopersicum L.) originated in }} \\
\hline & Dry weight; & & \\
\hline \multirow{2}{*}{$\begin{array}{l}\text { SW: } \\
\text { IL: }\end{array}$} & Steam width; & \multirow{8}{*}{\multicolumn{2}{|c|}{$\begin{array}{l}\text { South America. It is widely cultivated in the field and } \\
\text { greenhouse as one of the most important vegetables in } \\
\text { the world. But it is sensitive to heat. During growth } \\
\text { and development, the optimum temperatures in the } \\
\text { day for tomato are between } 25^{\circ} \mathrm{C} \text { and } 30^{\circ} \mathrm{C} \text { and at } \\
\text { night are } 20^{\circ} \mathrm{C}[1] \text {. When the temperature surpasses } \\
\text { the optimum temperature, its growth and production }\end{array}$}} \\
\hline & Internode length; & & \\
\hline \multirow{2}{*}{$\begin{array}{l}\text { FSR: } \\
\text { DMP: }\end{array}$} & Fruit setting rate; & & \\
\hline & Dry matter percentage; & & \\
\hline HII: & Heat injury index; & & \\
\hline \multirow{2}{*}{$\begin{array}{l}\text { HTC: } \\
\text { GP: }\end{array}$} & Heat tolerance coefficient; & & \\
\hline & Germination power; & & \\
\hline GR: & Germination rate; & & \\
\hline
\end{tabular}


greenhouse effect in the world, researches on tomato thermo-tolerance become increasingly important. While, the ability of heat resistance for plants is closely related to its genotype and growth developmental periods $[1,4$, 5], and exploring an effective evaluation ways for tomato thermo-tolerance can speed up the process of tomato heat-resistance breeding.

Germination is the original stage in the development of tomato, and the optimum germination temperature is between $25{ }^{\circ} \mathrm{C}$ and $30{ }^{\circ} \mathrm{C}$ [6]. A study found that the germination for tomato seeds in different temperature was remarkably different, and $34{ }^{\circ} \mathrm{C}$ could be regarded as the best temperature that divides thermo-tolerance levels of different tomato genotypes [7].

When the temperature is above $40{ }^{\circ} \mathrm{C}$, tomato plants will stop growing. The leaves of tomato become wilting and also present a state of water logging. The internode length (IL) becomes slender. The root system shrinks or stops growing. Because the germination of tomato seeds and growth of seedlings will present abnormal under high temperature, the germination and seedling growth indexes can be used to evaluate thermo-tolerance of tomato.

In flowering period, tomato is more sensitive to temperature, especially 3-4 d after it has flowered. When the temperature surpasses $30^{\circ} \mathrm{C}$ in the day and $20{ }^{\circ} \mathrm{C}$ at night, the inflorescence number of per spike will decrease, the node will rise and the dropping of flowers and fruits is very serious [8]. In addition, because of the self-pollination rates can reach above to 98\% in tomato, the stigma extends and the flower setting rate decreases with low number of seeds in fruit [9].

Thermo-tolerance is a quantitative trait controlled by multiple genes in plants [5], which is affected by the complex degree of environment conditions and the adaption ability in high temperature. Therefore, an evaluation system that was only dependent on the comparison of single or few indexes could not reliably reflect the thermo-tolerance of the plants. And too much indexes will make it confused and difficult. Principal component analysis (PCA) can transform numerous original indexes to few new and independent indexes that can represent the previous original indexes, and then combining with subordinate functions (SF), the deep ties to each index can be fully used to offsets and relieve the one-sidedness for using single index to evaluate. This comprehensive method has been used for chilling tolerance evaluation in tomato [10], cucumber [11], wheat [12] and cotton [13], but not in tomato thermo-tolerance. However, this comprehensive method has some loopholes. Firstly, the index used for PCA did not apply positive treatment and it may bring error in the final score. Secondly, after PCA analysis, some information would be cut down and the dimensionality reduction (DR) may create deviation in the final $D$ value, and few people tested the degree of the deviation. Moreover, the steps of this method are operated cumbersome, so a more simple method for evaluation was needed. Therefore, it is necessary to do the positive treatment for the corresponding indexes and no dimensionality reduction (NDR) comprehensive evaluation analysis. In this way, an exact result can be obtained. And on this basis, establishing a new method is very necessary.

In this research, the growth indexes at germination, seedling and flowering stages were measured. Combining with $t$ test, PCA (DR and NDR), SF, cluster analysis, correlation analysis and so on, the authors established a new simple, stable and reliable identification method for tomato thermo-tolerance. Finally, the consistency and relevance of thermo-tolerance at germination, seedling and flowering stages were discussed.

\section{Materials and Methods}

\subsection{Plant Materials}

30 different tomato genotypes were respectively obtained from America, Canada and China, as shown in Table 1. The 30 different tomato genotypes belong 
to two different species. S. lycopersicum is the cultivated tomato and S. pimpinellifolium is a kind of wild tomato which is currant tomato.

\subsection{Experimental Method}

\subsubsection{Evaluating of Thermo-Tolerance at} Germination Stage

The experiment began in Nanjing Agriculture University in April, 2014. Prior to germination, plump tomato seeds were chose. Seeds were then soaked for $8 \mathrm{~h}$ in water. After, 20 seeds were put on a filter paper uniformly in a culture dish with three repetitions for each genotype. And the culture dishes were placed in a manual climatic chamber (RDN-560E-4, Dongnan Instrument Co., Ltd., Ningbo, China) at $28{ }^{\circ} \mathrm{C}$ for control and $34{ }^{\circ} \mathrm{C}$ for high temperature treatment to detect the thermo-tolerance of the genotypes at germination stage. There was no illumination during the germination stage, and the seeds were watering every day. The number of germinated seeds was recorded every day, and the germination power (GP), germination rate (GR) and germination index (GI) were respectively calculated according to Eqs. (1)-(3):

$$
\text { GP }(\%)=\frac{\text { No. of germinating seeds on the } 4 \text { th day }}{\text { No. of the supplied seeds }}
$$

$$
\begin{gathered}
\text { GR }(\%)=\frac{\text { No. of germinating seeds on the } 7 \text { th day }}{\text { No. of the supplied seeds }} \\
\text { GI }=\sum \frac{G t}{D t}
\end{gathered}
$$

where, Gt represents the number of germination seeds on the $t$ day and $D t$ represents the corresponding germination days.

2.2.2 Evaluating of Thermo-Tolerance at Seedling Stage

\subsubsection{Seedlings Culturing and Treatment}

Seeds were soaked on April 15, 2014. When the radicles appeared, seeds were sowed into the 72 aperture disks. Seedlings were grown in aperture disks containing peat, vermiculite and perlite $(2: 1: 1 \mathrm{v} / \mathrm{v} / \mathrm{v})$. When the cotyledons of the seedlings unfolded, the seedlings were irrigated with $1 / 2 \times$ Hoagland nutrient solution. When cotyledon flatted, 1/2× Hoagland nutrient solution was supplied every two days. When the euphylla appeared, $1 \times$ Hoagland nutrient solution was supplied every two days.

When seedlings have three to four leaves, they were transferred from the greenhouse to a climatic chamber (RDN-560E-4, Dongnan Instrument Co., Ltd., Ningbo, China). The seedlings of the 30 tomato genotypes

Table 1 The details of 30 different tomato genotypes.

\begin{tabular}{llllllll}
\hline No. & Accession & Species & Resource & No. & Accession & Species & Resource \\
\hline 1 & Pole Red Siberian & S. lycopersicum & America & 16 & No name & S. lycopersicum & CH-JS \\
2 & Red cherry & S. lycopersicum & America & 17 & No name & S. lycopersicum & CH-JS \\
3 & Super sweet 100 & S. lycopersicum & America & 18 & No name & S. lycopersicum & CH-JS \\
4 & Super sweet 100 hybrid & S. lycopersicum & America & 19 & No name & S. lycopersicum & CH-JS \\
5 & Tomato cherry super sweet 100 & S. lycopersicum & America & 20 & No name & S. lycopersicum & CH-JS \\
6 & Tomato grape Telly bean red & S. lycopersicum & America & 21 & No name & S. lycopersicum & CH-JS \\
7 & Tomato cherry gardener's delight & S. lycopersicum & America & 22 & No name & S. lycopersicum & CH-JS \\
8 & Yellow pear & S. lycopersicum & America & 23 & No name & S.lycopersicum & CH-JS \\
9 & Mini red 1 & S. lycopersicum & Canada & 24 & AlsaGma & S. lycopersicum & CH-JS \\
10 & Mini red 2 & S. lycopersicum & Canada & 25 & LA1994 & S. lycopersicum & TGRC \\
11 & Witte HeNa & S. lycopersicum & Canada & 26 & LA2093 & S. pimpinellifolium & TGRC \\
12 & Witte Romana & S. lycopersicum & Canada & 27 & LA2661 & S. lycopersicum & TGRC \\
13 & Witte Sabata & S. lycopersicum & Canada & 28 & LA2683 & S. lycopersicum & TGRC \\
14 & Cherry super sweet & S. lycopersicum & CH-JS & 29 & LA3120 & S. lycopersicum & TGRC \\
15 & Qin Huang Fen Tian Shi & S. lycopersicum & CH-JS & 30 & LA3183 & S. lycopersicum & TGRC \\
\hline CH-JSR
\end{tabular}

CH-JS: Su Jiang, China; TGRC: C. M. Rick Tomato Genetic Resources Center, Department of Vegetable Crops, University of California, Davis. 
were exposed to $25^{\circ} \mathrm{C} / 15^{\circ} \mathrm{C}(14 \mathrm{~h} / 10 \mathrm{~h}$ for day/night $)$ and $40{ }^{\circ} \mathrm{C} / 28{ }^{\circ} \mathrm{C}(14 \mathrm{~h} / 10 \mathrm{~h}$ for day/night $)$ for $7 \mathrm{~d}$ in the climatic chamber with $60 \%$ relative humidity $(\mathrm{RH})$ and $375 \mu \mathrm{mol} / \mathrm{m}^{2} \cdot \mathrm{s}$ photosynthetic photon flux density (PPFD). There were 24 seedlings of each genotype subdivided into two treatments (normal and high temperature) and three replications with four seedlings per treatment.

\subsubsection{Determination of Growth Indexes}

After $7 \mathrm{~d}$ treatments, internode length (IL), steam width (SW), fresh weight (FW) of shoot, dry weight (DW) of shoot, FW of root and DW of root were measured. The IL was measured by a ruler with a unit of mm. The SW (the second node above the cotyledon) was measured by a vernier caliper.

The fresh weight aboveground and underground were measured by an electronic balance, and then the two parts were dried to a constant weight and measured by the electronic balance. The dry matter percent (DMP) of seedling was calculated using Eq. (4):

$$
\text { DMP of seedling }=\left(\mathrm{DW}_{\mathrm{s}} / \mathrm{FW}_{\mathrm{s}}\right) \times 100 \%
$$

where, FWs is the fresh weight of seeding aboveground and underground, and DWs is seeding dried to a constant weight.

Heat injury index (HII) of tomato seedlings were identified according to the method of Hong et al. [14] with some modifications. They were divided into five levels: $0-$ no wilted leaves; $1-20 \%$ of the leaves appear slightly wrinkled or wilted; 2 - the main stems grow well, but $50 \%$ of the leaves are wilted; $3 \longrightarrow 50 \%$ of the leaves are wilted; 4-the entire seedling is wilted or dead. And HII was calculated according to Eq. (5):

$\mathrm{HII}=\sum \frac{X_{a}}{\left(n \sum X\right)}=\left(X_{1} a_{1}+X_{2} a_{2}+\cdots+X_{n} a_{n}\right) / n T$

where, $X_{n}$ represents the number of seedlings with the same level of heat injury, $a_{n}$ indicates the level of heat injury, $n$ represents the total number of tomato seedlings of each replication, and $T$ represents the highest level (the fourth level).

\subsubsection{Evaluating of Thermo-Tolerance at Flowering} Stage

When the seedlings grew to four to five leaves, they were transplanted to the Jiangpu test field of Nanjing Agriculture University. Each tomato genotype had three replicates with two plants in each repetition. To explore the fruit setting rate (FSR) under high temperature, it was investigated in the third inflorescence at the end of July and the beginning of August.

\subsection{Statistic Analysis}

$F$ test, variation analysis and correlation analysis were carrying out using IBM SPSS statistics. Differences between the control and the heat treatment were tested with Student's $t$ test. The significant difference level between control and heat treatments was set at 0.05 and 0.01 .

All the growth indexes of tomato genotypes were expressed as the heat tolerance coefficient (HTC), except HII and FSR. HTC was calculated as Eq. (6):

$$
\mathrm{HTC}=\frac{\text { the index value of the treatment }(\mathrm{T})}{\text { the index value of the control }(\mathrm{CK})}
$$

The indexes for HTC at seedling stage include three types. The first type is positive indicators, containing FW of shoot, root and seedling. The second type is moderate indicators, containing DMP of shoot, root and seedling and IL. The last type is negative indicator which contains only one index HII. In order to guarantee the consistency for all the HTCs, the moderate and negative HTCs need a positive treatment. The moderate indicators applied a positive treatment were calculated as $-\left|X_{n}-k\right|$; while, the negative indicators applied a positive treatment were calculated as $-X_{n}$, where $X_{n}$ indicates HTC in different tomato genotypes and $k$ indicates the optimal value of HTC $(k=1)$. Then, the HTCs after positive treatment at germination and seedling stage were standardized by Z-score. Then PCA and cluster analysis (version 20.0, BM Corp. released in 2011) were carried out to 
screen out the principal component and identify the thermo-tolerance of each genotype. The pictures for cluster and correlation analysis were created by HemI 1.0, and other pictures were created by Origin 9.0.

The score coefficient of each index of principal components (PCs) were calculated according to Eq. (7):

$$
\text { Score coefficient }(C)=\frac{L}{\sqrt{\lambda}}
$$

where, $L$ indicates the load of each index in PCs and $\lambda$ indicates the eigenvalue for corresponding PCs.

The score of PCs were calculated according to Eq. (8):

$$
\mathrm{PCs}=\sum\left(C_{j} \times N_{j}\right)(j=1,2,3, \ldots, n)
$$

where, $C_{j}$ indicates the score coefficient of the $j$ th index (HTC) of PCs and $N$ indicates the standardized data of $j$ th index (HTC).

SF values $(U)$ were calculated according to Eq. (9):

$$
U\left(X_{j}\right)=\frac{\left(X_{j}-X_{\min }\right)}{\left(X_{\max }-X_{\min }\right)}(j=1,2, \ldots, n)
$$

where, $X_{j}$ indicates the score of the $j$ th comprehensive indicator, $X_{\min }$ indicates the minimum score of the $j$ th comprehensive indicator and $X_{\max }$ indicates the maximum score of the $j$ th comprehensive indicator.

Weights of the comprehensive indexes $(W)$ were calculated based on Eq. (10):

$$
W_{j}=\frac{I_{j}}{\sum I_{j}}(j=1,2, \ldots, n)
$$

where, $I_{j}$ indicates the contribution rate of the $j$ th comprehensive indicator of the different tomato genotypes.

The comprehensive evaluation values $(D)$ of different tomato genotypes were calculated according to Eq. (11):

$$
D=\sum\left(U_{j} \times W_{j}\right)(j=1,2, \ldots, n)
$$

where, $D$ indicates the comprehensive evaluation value for heat tolerance in the tomato genotypes that exposed to heat stress.

In order to compare the consistency of the results between $\mathrm{PCA}_{(\mathrm{DR})}$ and $\mathrm{PCA}_{(\mathrm{NDR})}$, the side sameness $(S)$ [15] was computed according to Eq. (12) based on Pareto principle [16]:

$$
S=\frac{(X+Y)}{0.4 M}
$$

where, $X$ and $Y$ indicate the number of the common tomato genotypes between $\mathrm{PCA}_{(\mathrm{DR})}$ and $\mathrm{PCA}_{(\mathrm{NDR})}$ in the best and worst $20 \%$ for thermo-tolerance, respectively. $M$ indicates the total number of tomato genotypes. The range of $S$ is from 0 to 1 , and the bigger it is, the better for the consistency it is.

\section{Result}

3.1 Analyses of the Growth Indexes of Tomato Genotypes Exposed to Heat Stress at Germination, Seedling and Flowering Stage

All the indexes at germination, seedling and flowering stage were measured in the 30 tomato genotypes. $F$ test showed all the indexes could distinguish the tomato genotypes well $(P<0.01)$. At germination stage, the average coefficient of variance was 0.52 (control) and 1.31 (treatment). At seedling stage, it was 0.27 (control) and 0.33 (treatment). At flowering stage, it was 0.27 (treatment). Variation analysis showed that with the higher coefficient of variance after the high temperature treatment, all indexes could reflect the difference in thermo-tolerance, and be used to evaluate the thermo-tolerance of tomato genotypes. Then the differences between control and heat treatment of indexes were compared with the Student's $t$ test (Table 2). The results showed that no matter at germination or seedling stage, most of the indexes were different in the same tomato genotype. For example, at germination stage, as for the tomato genotype No. 1 (Pole Red Siberian), the GR and GP did not have significant difference between heat stress and control, which indicated that GR and GP of genotype No. 1 were not affected under the heat stress, and genotype No. 1 showed a resistance in germination stage. But, GI 
Table 2 The statistical significance of the differences between the control and the heat treatment for the measured parameters by the Student's $t$ test.

\begin{tabular}{|c|c|c|c|c|c|c|c|c|c|c|c|c|c|c|c|c|}
\hline No. & GR & GP & GI & $\begin{array}{l}\text { FW of } \\
\text { shoot }\end{array}$ & $\begin{array}{l}\text { DW of } \\
\text { shoot }\end{array}$ & $\begin{array}{l}\mathrm{FW} \text { of } \\
\text { root }\end{array}$ & $\begin{array}{l}\text { DW of } \\
\text { root }\end{array}$ & $\begin{array}{l}\text { FW of } \\
\text { seedling }\end{array}$ & $\begin{array}{l}\text { DW of } \\
\text { seedling }\end{array}$ & $\begin{array}{l}\text { DMP of } \\
\text { shoot }\end{array}$ & $\begin{array}{l}\text { DMP of } \\
\text { root }\end{array}$ & $\begin{array}{l}\text { DMP of } \\
\text { seedling }\end{array}$ & SW & IL & HII & FSR \\
\hline 1 & & & $* *$ & $* *$ & $*$ & $* *$ & $* *$ & $* *$ & $* *$ & $*$ & & $* *$ & & & 0.75 & 0.32 \\
\hline 2 & $* *$ & $* *$ & $* *$ & $* *$ & & $* *$ & $*$ & $* *$ & & & $*$ & $*$ & & & 0.38 & 0.69 \\
\hline 3 & $* *$ & $*$ & & $*$ & & $*$ & $*$ & $*$ & & $*$ & & $* *$ & & & 0.48 & 0.52 \\
\hline 4 & $* *$ & $* *$ & $* *$ & $*$ & $* *$ & & & $*$ & $* *$ & & & & & & 0.48 & 0.58 \\
\hline 5 & $* *$ & $* *$ & $*$ & $* *$ & & & $*$ & $* *$ & & & & & & & 0.38 & 0.75 \\
\hline 6 & $* *$ & $* *$ & $* *$ & $* *$ & $*$ & $*$ & & $* *$ & $*$ & & & & & & 0.46 & 0.58 \\
\hline 7 & $* *$ & $* *$ & $* *$ & $* *$ & $* *$ & $*$ & $* *$ & $* *$ & $* *$ & & & & $*$ & & 0.75 & 0.44 \\
\hline 8 & $* *$ & & & $* *$ & $* *$ & $* *$ & $*$ & $* *$ & $* *$ & & $* *$ & & $*$ & & 0.31 & 0.42 \\
\hline 9 & $* *$ & $* *$ & $* *$ & $* *$ & $* *$ & $* *$ & $* *$ & $* *$ & $* *$ & & $* *$ & $*$ & & $*$ & 0.54 & 0.53 \\
\hline 10 & & & $* *$ & $* *$ & $*$ & $* *$ & & $* *$ & & & & & $*$ & & 0.44 & 0.55 \\
\hline 11 & $* *$ & $* *$ & $* *$ & $* *$ & $* *$ & $*$ & $* *$ & $* *$ & $* *$ & $*$ & $*$ & $* *$ & $* *$ & & 0.38 & 0.46 \\
\hline 12 & $* *$ & $* *$ & $* *$ & $* *$ & $* *$ & $* *$ & $* *$ & $* *$ & $* *$ & $* *$ & $* *$ & $* *$ & $*$ & $*$ & 0.48 & 0.45 \\
\hline 13 & & & $* *$ & $*$ & & & $*$ & $* *$ & & & $*$ & & $* *$ & & 0.17 & 0.77 \\
\hline 14 & $* *$ & $*$ & $*$ & $* *$ & $*$ & $*$ & $* *$ & $* *$ & $* *$ & $*$ & & $* *$ & & $* *$ & 0.10 & 0.70 \\
\hline 15 & $*$ & $*$ & & $* *$ & $* *$ & $* *$ & & $* *$ & $* *$ & & $*$ & & $* *$ & & 0.29 & 0.56 \\
\hline 16 & $* *$ & $* *$ & $* *$ & $*$ & & $* *$ & $*$ & $*$ & & & $*$ & & $*$ & & 0.73 & 0.55 \\
\hline 17 & $*$ & $*$ & & $* *$ & $*$ & $* *$ & $*$ & $* *$ & $* *$ & & & $*$ & $* *$ & & 0.15 & 0.74 \\
\hline 18 & $* *$ & $* *$ & $* *$ & $* *$ & $* *$ & $* *$ & $* *$ & $* *$ & $* *$ & & & $*$ & $* *$ & & 0.42 & 0.53 \\
\hline 19 & $* *$ & $*$ & $*$ & $*$ & $* *$ & $* *$ & $*$ & $*$ & $* *$ & & & & $*$ & & 0.60 & 0.53 \\
\hline 20 & & & & $* *$ & $* *$ & $*$ & $* *$ & $* *$ & $* *$ & & & & $* *$ & $*$ & 0.21 & 0.53 \\
\hline 21 & & & & $*$ & $* *$ & $* *$ & $* *$ & $* *$ & $* *$ & & $*$ & & $*$ & & 0.48 & 0.34 \\
\hline 22 & $* *$ & $* *$ & $* *$ & $* *$ & $* *$ & & & $*$ & $* *$ & & & & $*$ & & 0.40 & 0.38 \\
\hline 23 & $* *$ & $* *$ & $* *$ & $* *$ & $* *$ & & $*$ & $*$ & $* *$ & & & & & $* *$ & 0.58 & 0.50 \\
\hline 24 & $* *$ & $*$ & $*$ & $* *$ & $* *$ & $* *$ & $* *$ & $* *$ & $* *$ & & & & $*$ & $*$ & 0.54 & 0.54 \\
\hline 25 & $* *$ & $* *$ & & $* *$ & $* *$ & $* *$ & $* *$ & $* *$ & $* *$ & $* *$ & $* *$ & $* *$ & $* *$ & & 0.15 & 0.52 \\
\hline 26 & & & $* *$ & & & $*$ & $* *$ & $*$ & $* *$ & & & & $* *$ & & 0.08 & 0.76 \\
\hline 27 & $* *$ & $* *$ & $* *$ & $* *$ & $* *$ & $* *$ & $* *$ & $* *$ & $* *$ & $*$ & $*$ & $* *$ & $* *$ & & 0.58 & 0.57 \\
\hline 28 & & & $*$ & $* *$ & $* *$ & $* *$ & $* *$ & $* *$ & $* *$ & & $*$ & & & & 0.75 & 0.41 \\
\hline 29 & $* *$ & $* *$ & $* *$ & $* *$ & $* *$ & $* *$ & $* *$ & $* *$ & $* *$ & $*$ & $*$ & $* *$ & $* *$ & $* *$ & 0.42 & 0.43 \\
\hline 30 & $* *$ & $* *$ & $* *$ & $* *$ & $* *$ & $* *$ & $*$ & $* *$ & $* *$ & & & & $*$ & & 0.56 & 0.56 \\
\hline
\end{tabular}

** significant difference at the 0.01 level $(P<0.01) ; *$ significant difference at the 0.05 level $(P<0.05)$.

was significant difference for this tomato genotype, which indicated that GI was affected and the progress of seed germination was restrained, so the genotype No. 1 showed its sensitivity under heat stress. At seedling stage, as for the tomato genotype No. 26 (LA2093), the FW and DW of shoot, DMP of shoot, root and seedling, and IL did not have significant difference between heat stress and control, which indicated that FW and DW of shoot, DMP of shoot, root and seedling, and IL of genotype No. 26 were not affected under the heat stress, therefore genotype No. 26 showed a resistance at seedling stage. While, FW of root and seedling, DW of root and seedling, and SW were significantly different between heat stress and control, which indicated that FW of root and seedling, DW of root and seedling, and SW were affected and the progress of seedling growth was restrained, so the genotype No. 26 showed its sensitivity under heat stress. These results showed that different germination or seedling indexes on heat stress response were different, and also suggested that it was difficult to evaluate tomato thermo-tolerance systematically by using single index. Therefore, multiple indexes should be used for comprehensive evaluation. 
3.2 Comprehensive Evaluation of Thermo-Tolerance of Tomato at Germination, Seedling and Flowering Stage

\subsubsection{At Germination Stage}

In order to evaluate the thermo-tolerance of tomato germination more accurately, firstly, the HTC of the three germination indexes (GR, GP and GI) were calculated, and then the correlation analysis of all the three indexes were carried out. The result illustrated that all the three indexes had a significant positive correlation (Fig. 1). So the PCA was carried out to find the key indicators. Then the HTCs were standardized by the algorithm of $Z$-score. These standardized data were used for PCA, and the three growth indexes were transformed into three new independent components (Fig. 2). The eigenvalue of the principal component 1 ( $\mathrm{PC} 1)$ was greater than 1 (Fig. 2a), and its contributions reached to $97.957 \%$. The contributions of the rest two components (PC2 and PC3) were only $1.751 \%$ and $0.292 \%$, respectively, which could be ignored. The loads of the three indexes (GR, GP and GI) on the PC1 reached to $99 \%, 99.6 \%$ and $98.3 \%$, respectively, which illustrated that each of them could act as an indicator to evaluate the thermo-tolerance at germination stage. While the highest loads was GP on the PC1, indicating that it was the optimal index for the evaluation of germination thermo-tolerance (Fig. 2b). The germination optimal index $D$ value (GOID) was used for cluster analysis. With the shortest distance method, the 30 tomato genotypes can be clustered into three groups depending on Euclidean distance (Fig. 3a).

Combining with standardized data of HTC and score coefficient of PCs, the score of PCs were got. The SF value of PCs in different tomato genotypes was then computed. And the weight of the PCs was computed, according to the contributions of the PCs. Because there was only one PC, the weight of PC1 was 1 . Finally, the germination stage $D$ value by dimensionality reduction $\left(\mathrm{GSDV}_{(\mathrm{DR})}\right)$ was calculated. Correlation analysis showed that $\operatorname{GSDV}_{(\mathrm{DR})}$ had a significant positive correlation with the three growth indexes, illustrating that the $\operatorname{GSDV}_{(\mathrm{DR})}$ could replace the three indexes commendably (Fig. 1). Cluster analysis was applied to objectively classify the tomato genotypes based on their $\operatorname{GSDV}_{(\mathrm{DR})}$. With the shortest distance method, the 30 tomato genotypes can be clustered into three groups depending on Euclidean distance (Fig. 3b). The spatial distribution of the three groups can be seen in the two or three dimensional PCs (Fig. 2c), which showed that the group III (heat resistant) was partial to the high value district of PC1. While, the group I (heat sensitive) was partial to the low value district of $\mathrm{PC} 1$.

The three germination indexes had been reduced to the PC1 though the PCA. Although PC1 included most information of three germination indexes, the authors did not know that whether DR would influence on the evaluation of thermo-tolerance of seeds. Therefore, the NDR comprehensive assessment was conducted. The three components were retained, and the weight of three components was equal to their contributions, respectively. Finally, the germination stage $D$ value by no dimensionality reduction $\left(\mathrm{GSDV}_{(\mathrm{NDR})}\right)$ were computed. Cluster analysis was applied to objectively classify the tomato genotypes based on their GSDV $\mathrm{V}_{(\mathrm{NDR})}$. With the shortest distance method, the 30 tomato genotypes can be clustered into three groups too depending on Euclidean distance (Fig. $3 \mathrm{c})$. The members in each group were all the same to the above results (GSDV $(\mathrm{DR})$ and GOID), and the side sameness $(S)$ [15] was certainly 1 , which illustrated that after PCA, GSDV $(\mathrm{DR})$ and GOID could evaluate the thermo-tolerance of tomato seeds accurately, and GOID and DR reduced the workload.

\subsubsection{At Seedling Stage}

The same to the above analysis process, PCA was carried out for indexes of seedling. Because of existing moderate or negative HTCs, they were applied with a positive treatment. After standardization, PCA was applied and three PCs were achieved (Fig. 4a). Fig. 4b showed the spatial distribution of the 12 components in 


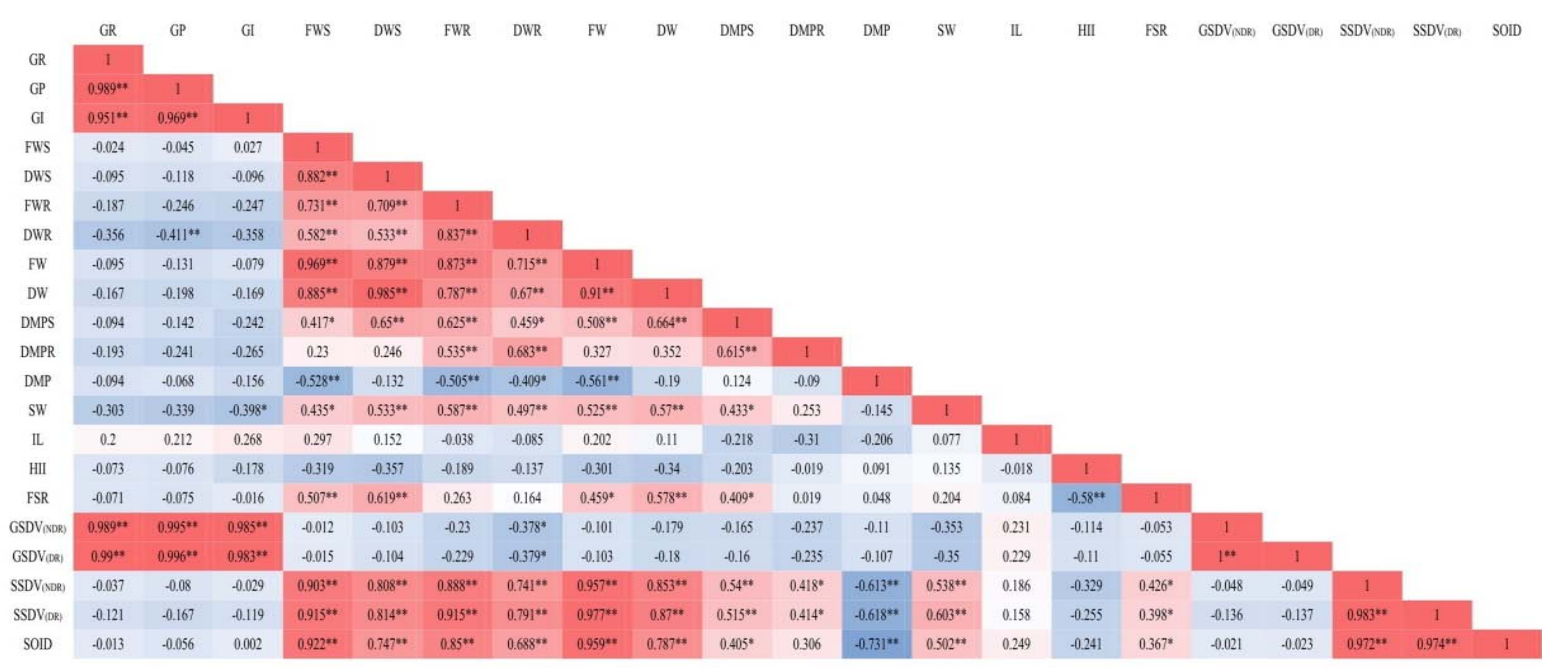

Fig. 1 Correlation analysis of germination, seedling and flowering stage.

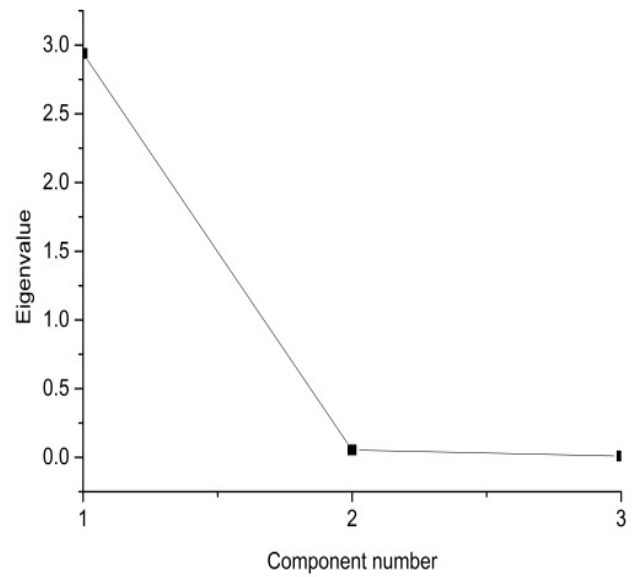

(a) The eigenvalue for PCs

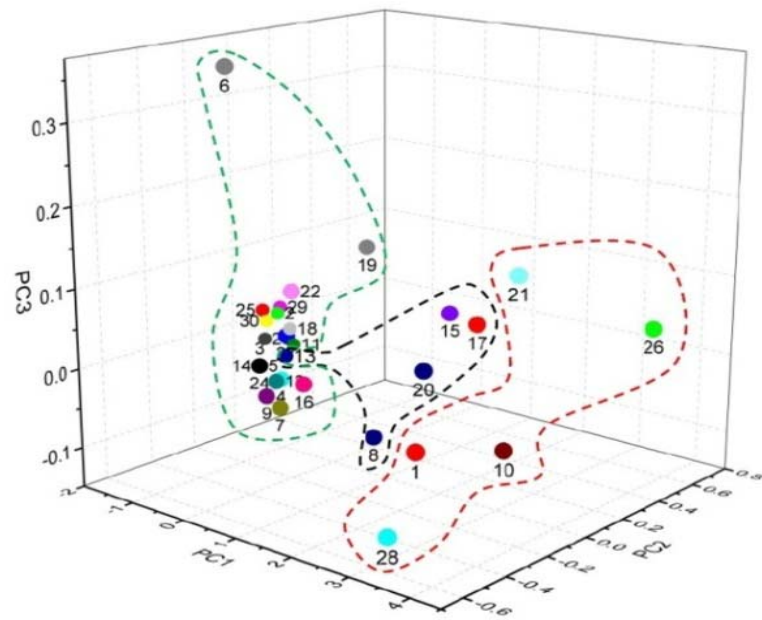

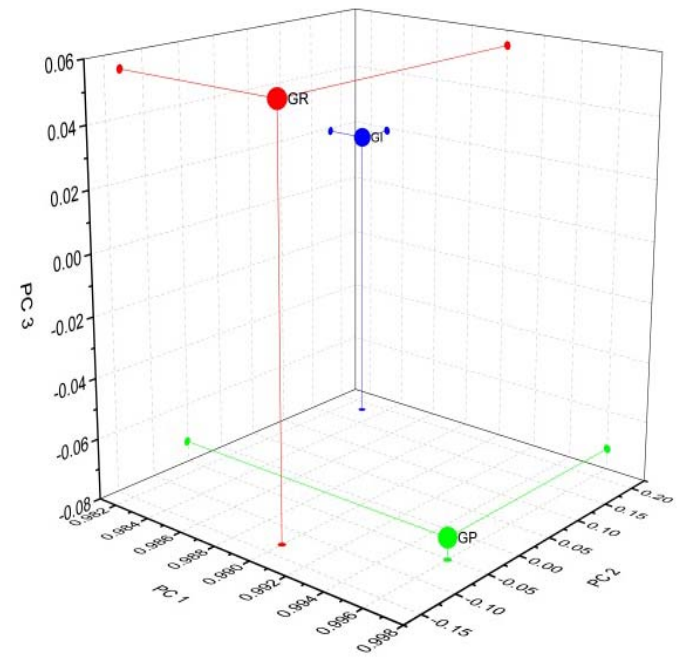

(b) The load for the indexes in the PCs

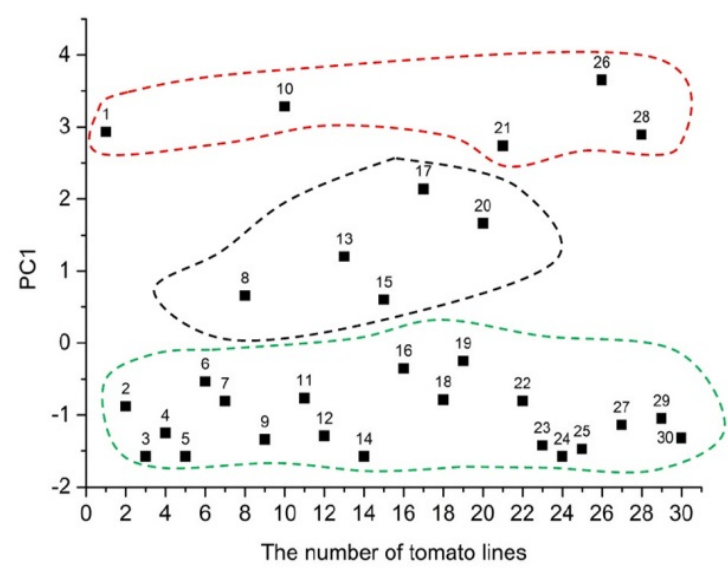

(c) The spatial distribution of the three groups in the two or three dimensional PCs

Fig. 2 PCA of germination stage in different tomato genotypes.

In Fig. 2c, green genotype: heat sensitive, black genotype: moderate heat resistant and red genotype: heat resistant. 

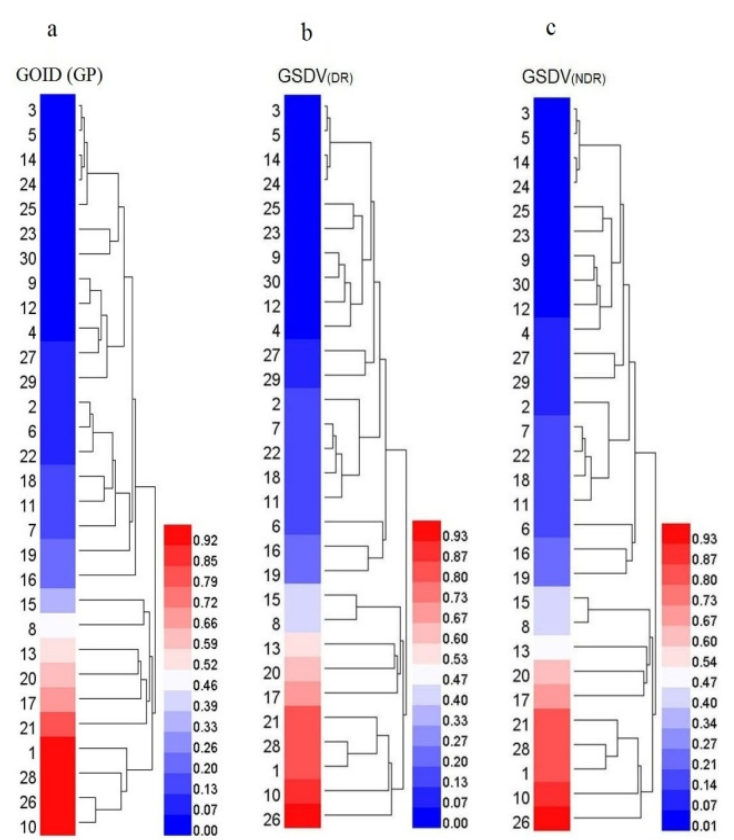

Fig. 3 Cluster analysis of comprehensive assessment $D$ value in different tomato genotypes at germination stage.

in three dimensional PCs. PC1 mainly reflected FW of seeding, and its contributions reached to $52.372 \%$. PC2 mainly reflected IL, and its contributions reached to $12.593 \%$. PC3 mainly reflected DMP of seeding and its contributions reached to $11.505 \%$. Here, three optimal indexes were got, including FW, IL and DMP. The total contribution of the three PCs was $76.469 \%$, and the other components were ignored. The weight of the three PCs was $0.685,0.165$ and 0.150 , respectively. Finally, the seedling stage $D$ value by dimensionality reduction $\left(\mathrm{SSDV}_{(\mathrm{DR})}\right)$ was computed. The $\mathrm{SSDV}_{(\mathrm{DR})}$

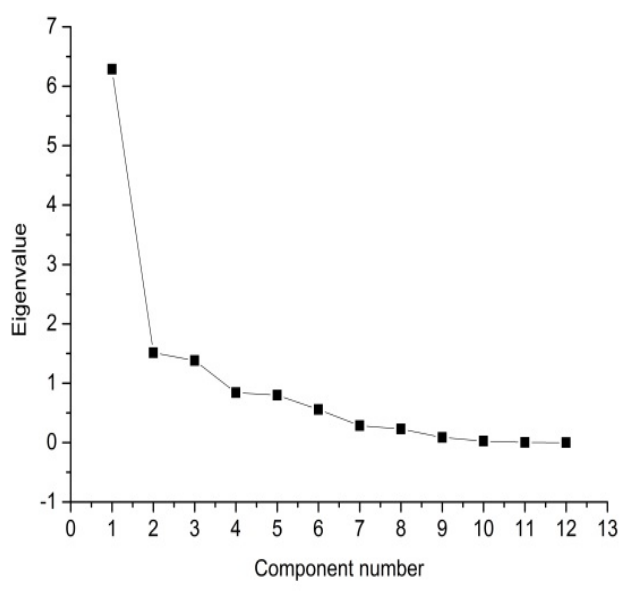

(a) The eigenvalue for PCs had significant positive correlations with 10 growth indexes, which showed that the $\operatorname{SSDV}_{(\mathrm{DR})}$ could replace the 10 indexes commendably. However, the $\mathrm{SSDV}_{(\mathrm{DR})}$ did not have significant correlations with the other indexes, including IL and HII (Fig. 1). That was because PC2 mainly reflected the two indexes (Fig. 4b), occupying small proportion in the $\operatorname{SSDV}_{(\mathrm{DR})}$. The spatial distribution of the three groups can be seen in the two and three dimensional PCs (Fig. 4c), which showed that the group IV (heat resistant) were partial to the high value district of PC1. While, the group I and II (heat sensitive) was partial to the low value district of PC1 (Fig. 4c). Cluster analysis was applied to objectively classify the tomato genotypes based on their $\operatorname{SSDV}_{(\mathrm{DR})}$. With the shortest distance method, the 30 tomato genotypes can be clustered into four groups depending on Euclidean distance (Fig. 5a).

The 12 seedling growth indicators had been reduced to three PCs. Then the NDR comprehensive assessment was conducted. The 12 components were retained and the seedling stage $D$ value by dimensionality reduction $\left(\mathrm{SSDV}_{(\mathrm{NDR})}\right)$ were computed. Cluster analysis was applied to objectively classify the tomato genotypes based on their $\operatorname{SSDV}_{(\mathrm{NDR})}$. With the Euclidean distance method, the 30 tomato genotypes can be clustered into five groups (Fig. 5b). The side sameness $(S)$ value between $\operatorname{SSDV}_{(\mathrm{DR})}$ and $\operatorname{SSDV}_{(\mathrm{NDR})}$ was 0.917 , which illustrated that after PCA, $\mathrm{SSDV}_{(\mathrm{DR})}$ could evaluate the thermo-tolerance of tomato seedlings accurately.

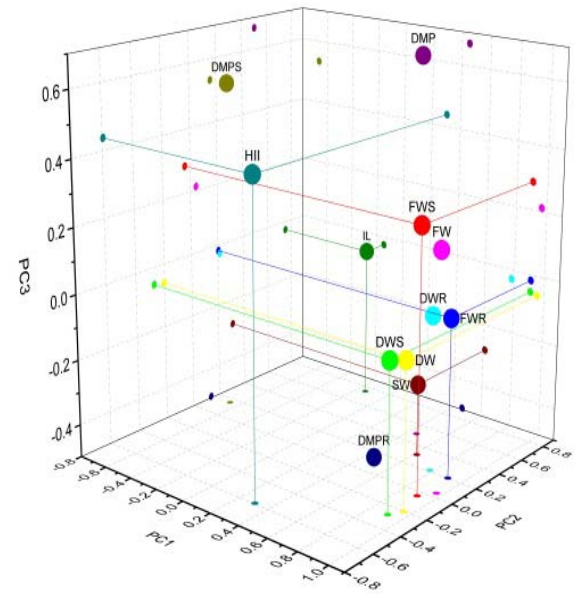

(b) The load for the indexes in the PCs 


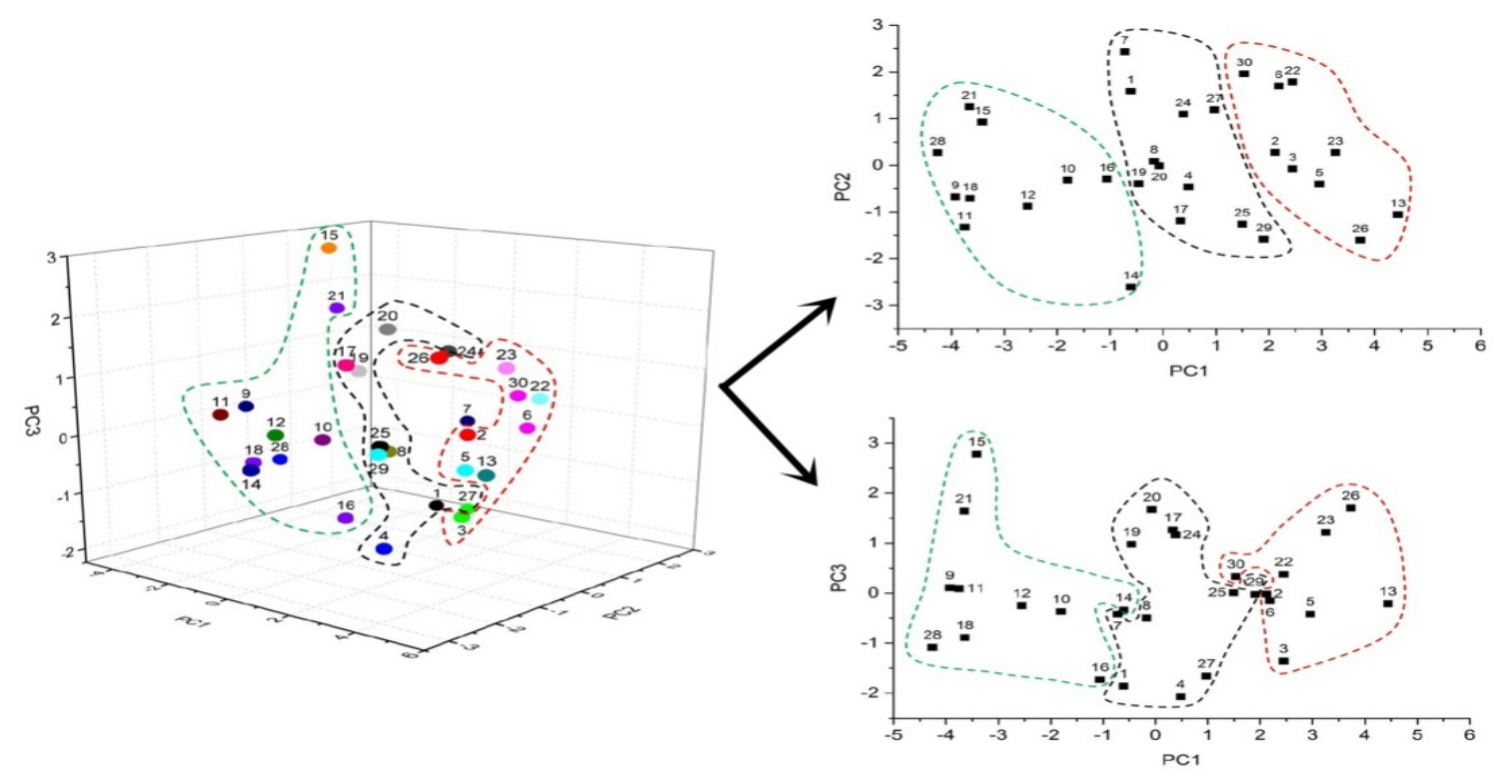

(c) The spatial distribution of the three groups in the two or three dimensional PCs

Fig. 4 PCA of seedling stage in different tomato genotypes.

In Fig. 4c, green genotype: heat sensitive, black genotype: moderate heat resistant and red genotype: heat resistant.

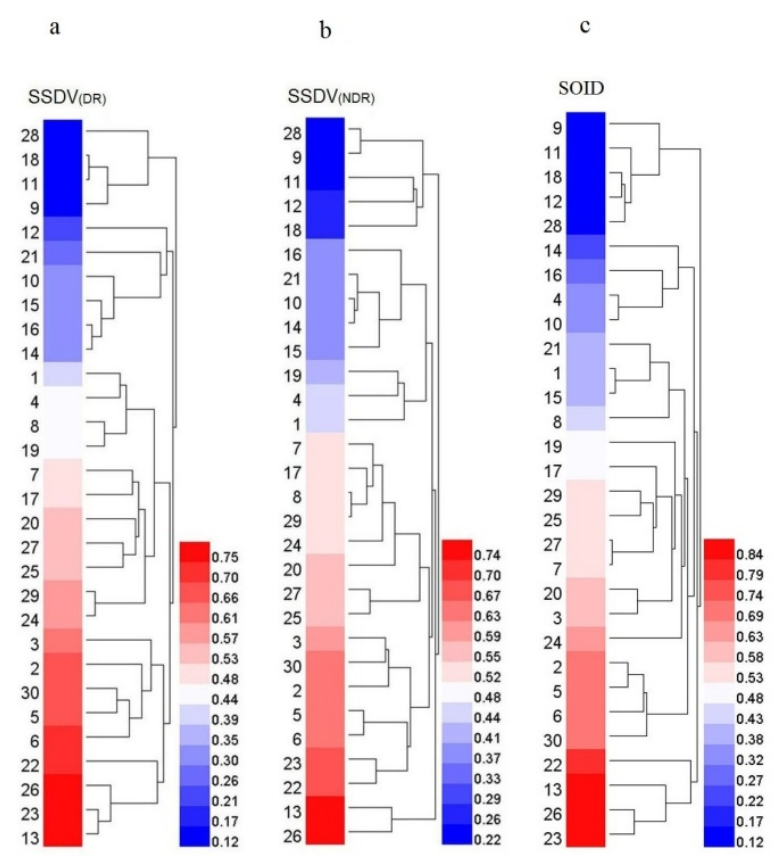

Fig. 5 Cluster analysis of comprehensive assessment $D$ value in different tomato genotypes at seedling stage.

Based on the above analysis, the optimal indexes were obtained. They were FW, IL and DMP. In order to further simplify the evaluation system, the three indicators (HTCs) were directly used for analysis, computing its $\mathrm{SF}$ value. Combining the weight of its corresponding PCs, the seedling optimal indexes $D$ value (SOID) were got. Cluster analysis was applied to objectively classify the tomato genotypes based on their SOID. With the shortest distance method, the 30 tomato genotypes can be clustered into six groups (Fig. 5c). The side sameness (S) value between $\operatorname{SSDV}_{(\mathrm{DR})}$ and SOID was 0.833, and between $\mathrm{SSDV}_{(\mathrm{NDR})}$ and SOID was 0.833 , too. Finally, the whole result of thermo-tolerance for 30 tomato genotypes at seedling stage based on the cluster analysis was got (Table 3), which showed that the three evaluation methods got almost the same results. SOID was one of the simplest methods for evaluation of thermo-tolerance of tomato.

\subsubsection{At Flowering Stage}

Cluster analysis was applied to objectively classify the tomato genotypes based on their FSR. With the average distance method, the 30 tomato genotypes can be clustered into three groups depending on Euclidean distance (Fig. 6).

\subsection{Correlation Analysis of Different Indexes at Germination, Seedling and Flowering Stage}

In order to research the correlation of germination, seedling and flowering stage, the correlation analysis 
for all indexes and $D$ values (DR) of the three stages were carried out (Fig. 1). The results found that GP showed a significant negative correlation with DW of root. GI showed a significant negative correlation with SW. However, GSDV $(\mathrm{DR}), \mathrm{GSDV}_{(\mathrm{NDR})}$ and GOID showed no significant correlation with $\operatorname{SSDV}_{(\mathrm{DR})}$, $\operatorname{SSDV}_{(\mathrm{DR})}$ and SOID; FSR showed significant positive correlations with $\mathrm{SSDV}_{(\mathrm{DR})}, \mathrm{SSDV}_{(\mathrm{NDR})}, \mathrm{SOID}, \mathrm{FW}$ of shoot and seedling, DW of shoot and seedling, and DMP of seedling. FSR showed significant negative correlation with HII. Therefore, thermo-tolerance of seedling stage had a significant positive correlation with thermo-tolerance of flowering stage, and thermo-tolerance of germination stage did not show significant correlation with thermo-tolerance of seedling stage and flowering stage.

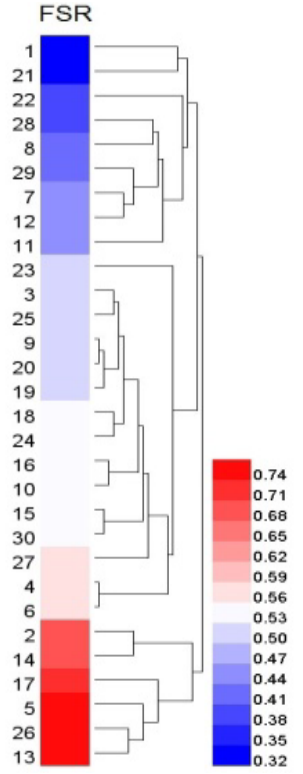

Fig. 6 Cluster analysis of fruit setting rate in different tomato genotypes.

Table 3 Thermo-tolerance of 30 tomato genotypes at germination, seedling and flowering stage.

\begin{tabular}{|c|c|c|c|c|c|c|c|}
\hline No. & $\begin{array}{l}\text { Germination } \\
\text { stage (NDR) }\end{array}$ & $\begin{array}{l}\text { Germination } \\
\text { stage (DR) }\end{array}$ & $\begin{array}{l}\text { Germination stage } \\
(\text { GOID }(\mathrm{GP}))\end{array}$ & $\begin{array}{l}\text { Seedling stage } \\
\text { (NDR) }\end{array}$ & $\begin{array}{l}\text { Seedling stage } \\
\text { (DR) }\end{array}$ & $\begin{array}{l}\text { Seedling stage (SOID } \\
(\mathrm{FW}, \mathrm{DMP}, \mathrm{IL}))\end{array}$ & $\begin{array}{l}\text { Flowering } \\
\text { stage }\end{array}$ \\
\hline 1 & HT & HT & HT & SHT & MHT & MHT & SHT \\
\hline 2 & SHT & SHT & SHT & HT & HT & HT & HT \\
\hline 3 & SHT & SHT & SHT & HT & HT & MHT & MHT \\
\hline 4 & SHT & SHT & SHT & SHT & MHT & SHT & MHT \\
\hline 5 & SHT & SHT & SHT & HT & HT & HT & HT \\
\hline 6 & SHT & SHT & SHT & HT & HT & HT & MHT \\
\hline 7 & SHT & SHT & SHT & MHT & MHT & MHT & SHT \\
\hline 8 & MHT & MHT & MHT & MHT & MHT & MHT & SHT \\
\hline 9 & SHT & SHT & SHT & SHT & SHT & SHT & MHT \\
\hline 10 & HT & HT & HT & SHT & SHT & SHT & MHT \\
\hline 11 & SHT & SHT & SHT & SHT & SHT & SHT & SHT \\
\hline 12 & SHT & SHT & SHT & SHT & SHT & SHT & SHT \\
\hline 13 & MHT & MHT & MHT & HT & HT & HT & HT \\
\hline 14 & SHT & SHT & SHT & SHT & SHT & SHT & HT \\
\hline 15 & MHT & MHT & MHT & SHT & SHT & MHT & MHT \\
\hline 16 & SHT & SHT & SHT & SHT & SHT & SHT & MHT \\
\hline 17 & MHT & MHT & MHT & MHT & MHT & MHT & HT \\
\hline 18 & SHT & SHT & SHT & SHT & SHT & SHT & MHT \\
\hline 19 & SHT & SHT & SHT & SHT & MHT & MHT & MHT \\
\hline 20 & MHT & MHT & MHT & MHT & MHT & MHT & MHT \\
\hline 21 & HT & HT & MHT & SHT & SHT & MHT & SHT \\
\hline 22 & SHT & SHT & SHT & HT & HT & HT & SHT \\
\hline 23 & SHT & SHT & SHT & HT & HT & HT & MHT \\
\hline 24 & SHT & SHT & SHT & MHT & MHT & MHT & MHT \\
\hline 25 & SHT & SHT & SHT & MHT & MHT & MHT & MHT \\
\hline 26 & HT & HT & HT & HT & HT & HT & HT \\
\hline 27 & SHT & SHT & SHT & MHT & MHT & MHT & MHT \\
\hline 28 & HT & HT & HT & SHT & SHT & SHT & SHT \\
\hline 29 & SHT & SHT & SHT & MHT & MHT & MHT & SHT \\
\hline 30 & SHT & SHT & SHT & HT & HT & HT & MHT \\
\hline
\end{tabular}

HT: heat tolerance; MHT: moderate heat tolerance; SHT: sensitive heat tolerance. 


\subsection{Prediction and Verification of Thermo-Tolerance of Tomato}

In order to prove the reliability of the evaluation system, 10 tomato genotypes were chosen from the 30 tomato genotypes, randomly. Firstly, the 10 tomato genotypes were tested at germination stage. The $\mathrm{GSDV}_{(\mathrm{NDR})}, \mathrm{GSDV}_{(\mathrm{DR})}$ and GP were used for cluster analysis, respectively (Fig. 7a). With the analysis, the 10 tomato genotypes were clustered into four groups by the $\mathrm{GSDV}_{(\mathrm{NDR})}, \mathrm{GSDV}_{(\mathrm{DR})}$ and GP, and the members for each corresponding groups were all the same. No. 5 was in group I; No. 30, 12, 27, 2, 11, 6 and 16 were in group II; No. 13 was in group III; No. 28 was in group IV. Afterwards, cluster analysis was applied to classify the tomato genotypes at $\mathrm{SSDV}_{(\mathrm{NDR})}$, $\operatorname{SSDV}_{(\mathrm{DR})}$, and SOID, respectively (Fig. 7b). The
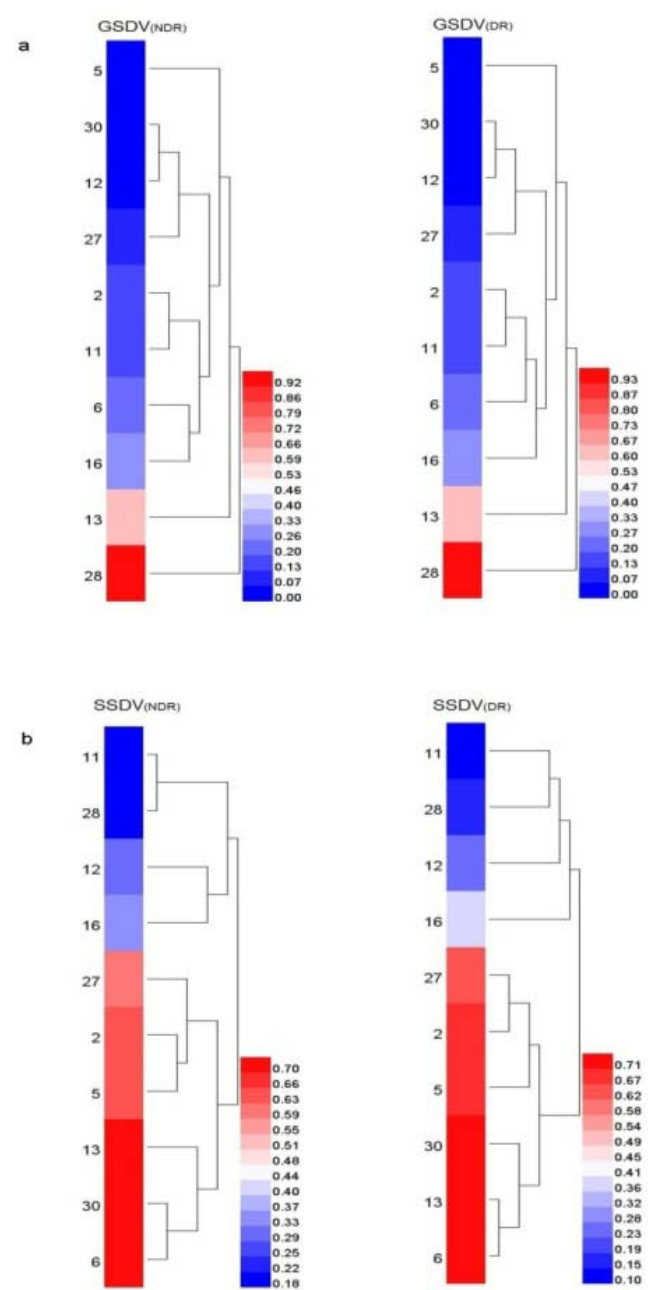

weight of each optimal indexes of seedling (FW, IL and DMP) was based on the contribution of $\mathrm{PC} 1$ (0.685), PC2 (0.165) and PC3 (0.150), respectively. The three indexes were used to replace the PC1, PC2 and PC3, respectively. The linear Eq. (13) was used for prediction in thermo-tolerance of tomato:

$$
D=0.685 \times \mathrm{SF} 1+0.165 \times \mathrm{SF} 2+0.150 \times \mathrm{SF} 3
$$

where, $D$ means the comprehensive evaluation value, and SF1, SF2 and SF3 are the subordinate function (SF) values of FW, IL and DMP, respectively.

Finally, the SOID was computed. The 10 tomato genotypes were clustered into three groups by the $\operatorname{SSDV}_{(\mathrm{NDR})}$. No. 11 and 28 were in group I; No. 12 and 16 were in group II; No. 27, 2, 5, 13, 30 and 6 were in group III. The $\operatorname{SSDV}_{(\mathrm{DR})}$ classified the 10 tomato genotypes into four groups. No. 11 and 28 were in group
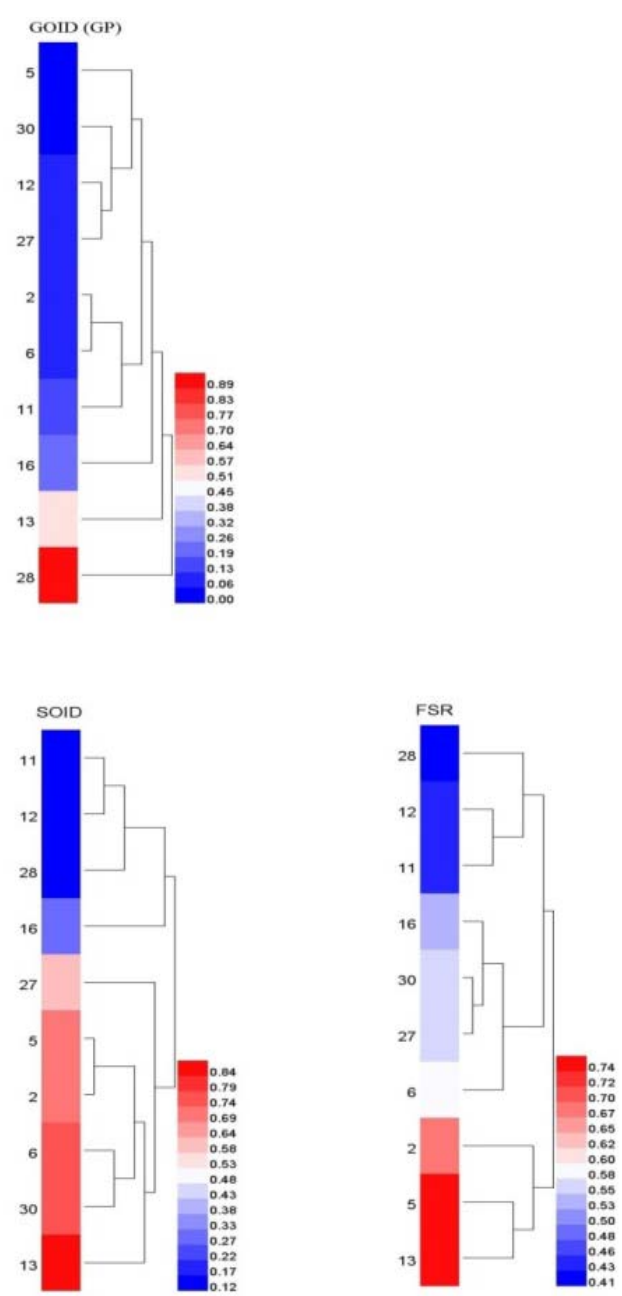

Fig. 7 Cluster analysis at germination, seedling and flowering stage for 10 tomato genotypes. 


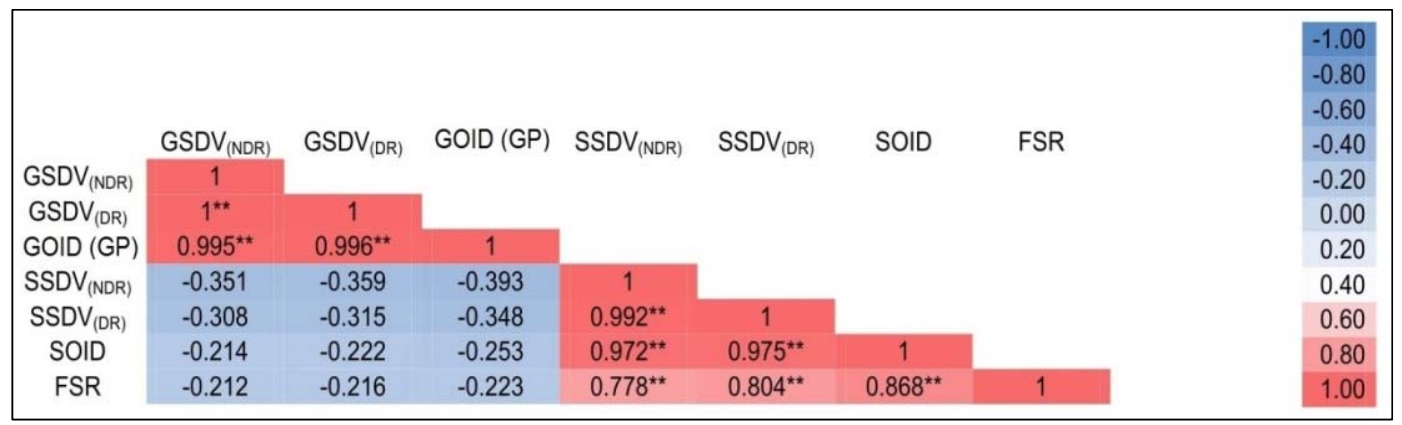

Fig. 8 Correlation analysis of germination, seedling and flowering stage for 10 tomato genotypes.

I; No. 12 was in group II; No. 16 was in group III; No. 27, 2, 5, 30, 13 and 6 were in group IV. The SOID classifies the 10 tomato genotypes into three groups. No. 11,12 and 28 were in group I; No. 16 was in group II; No. 27, 5, 2, 6, 30 and 13 were in group III. The $S$ value was not computed, for the sample size was only 10 . But as can be seen, although the groups were not the same, the members of the corresponding group are almost the same. Finally, the FSR classified the 10 tomato genotypes into three groups (Fig. 7b). No. 28, 12 and 11 were in group I; No. 16, 30, 27 and 6 were in group II; No. 2, 5 and 13 were in group III. In the end, the $\mathrm{GSDV}_{(\mathrm{NDR})}, \mathrm{GSDV}_{(\mathrm{DR})}$ and GP; $\mathrm{SSDV}_{(\mathrm{NDR})}, \mathrm{SSDV}_{(\mathrm{DR})}$ and SOID; and FSR were used to represent the germination, seedling and flowering stage, respectively, for correlation analysis (Fig. 8). It was also found that seedling stage showed a significant positive correlation with flowering stage, while, germination stage did not show significant correlation with seedling and flowering stage. In addition, the GP showed an extremely significant positive correlation with $\mathrm{GSDV}_{(\mathrm{NDR})}$ and $\mathrm{GSDV}_{(\mathrm{DR})}$; SOID showed an extremely significant positive correlation with $\operatorname{SSDV}_{(\mathrm{NDR})}$ and $\mathrm{SSDV}_{(\mathrm{DR})}$, which further indicated that GP could replace $\mathrm{GSDV}_{(\mathrm{NDR})}$ and $\mathrm{GSDV}_{(\mathrm{DR})}$, and SOID could replace $\mathrm{SSDV}_{(\mathrm{NDR})}$ and $\mathrm{SSDV}_{(\mathrm{DR})}$.

\section{Discussion}

\subsection{The Importance and Problem for Thermo-Tolerance Comprehensive Evaluation in Tomato}

High temperature is a common environment stress factor that adversely affects growth, development, reproduction and yield of almost all plant [17-21]. Therefore, it is important to evaluate the thermo-tolerance of plants. However, the application of different methods would get different results. Thermo-tolerance of plants is a quantitative character that controls by polygenes [5], which would be affected by complex environments and the adaptation ability of plants. Therefore, evaluating thermo-tolerance of plants with only a single index is susceptible to bias. Multiple comprehensive evaluation system can reduce the deviations, but will make it harder. Tomato often encounters the high temperature in the process of growth and development, which seriously influence seeds germination, seedling growth and fruit development. This process is complicated. It is important and hard to accurately evaluate the thermo-tolerance of tomato and screen out high temperature resistant genotypes. So establishing effective methods is very important. At present, the most commonly used comprehensive evaluation method for stress tolerance is the combination of PCA, SF, weight and clustering analysis [10-12]. While, there are some defects in the system. Before PCA, few people noticed that the indexes (negative or moderation direction) used for PCA should apply a positive treatment, or the result might create bias. In addition, after PCA, some information would be cut down, and the DR may create deviation in the final $D$ value and few people did not test the degree of the deviation. NDR analysis was essential to be tested. Furthermore, the existing method is so fussy. If the authors can simplify it and keep its accuracy, the 
efficiency of evaluation will be improved. Based on these points, this study put forward a new reasonable comprehensive evaluation system to improve the accuracy and efficiency of the results.

\subsection{A New Comprehensive Evaluation System Used for Thermo-Tolerance of Tomato}

Based on these problems, firstly, the traditional comprehensive evaluation method was modified, and

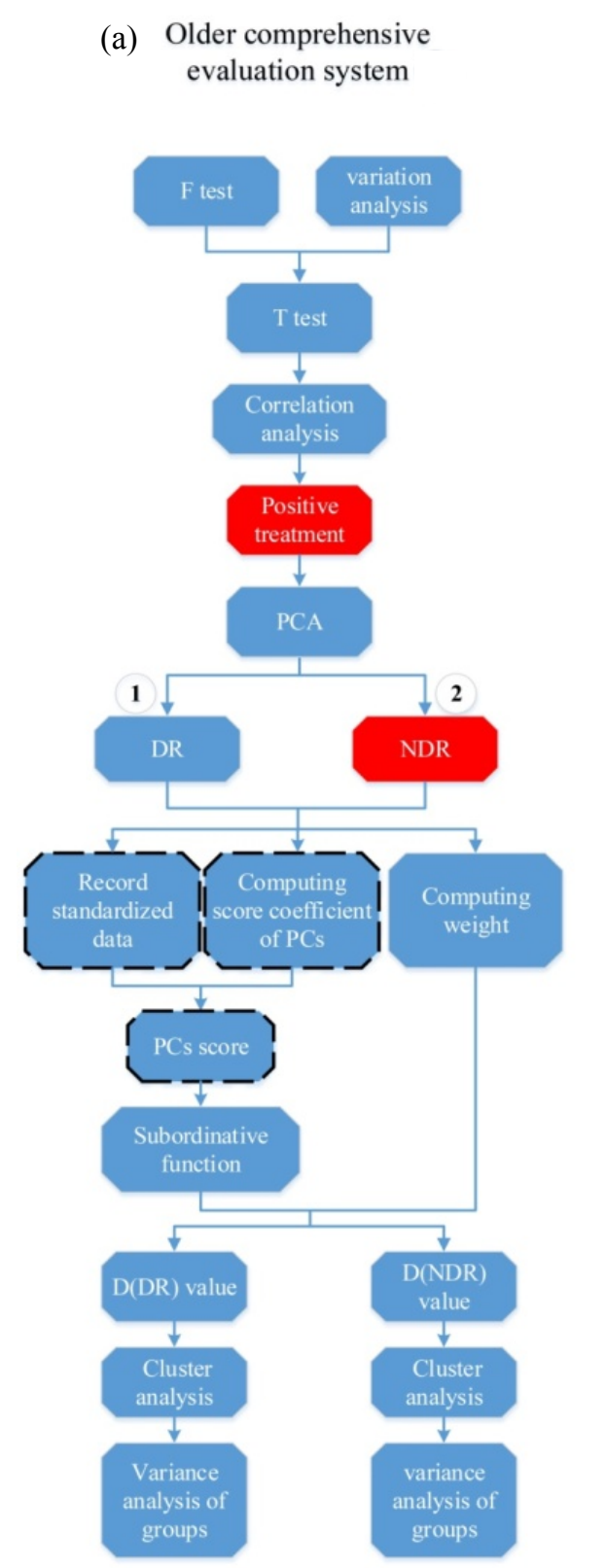

consistency issues for indexes as a key step were added in the evaluation (Fig. 9a). PCA is a data analysis method by reducing the dimensionality when large multivariate datasets are analyzed [22]. While, before PCA, it is important to perform a positive treatment to guarantee the consistency of the direction for all the indexes (the negative and moderation indexes). For example, in the research of Cao et al. [10], the PC3 mainly represented a negative index

(b) New comprehensive evaluation system

1
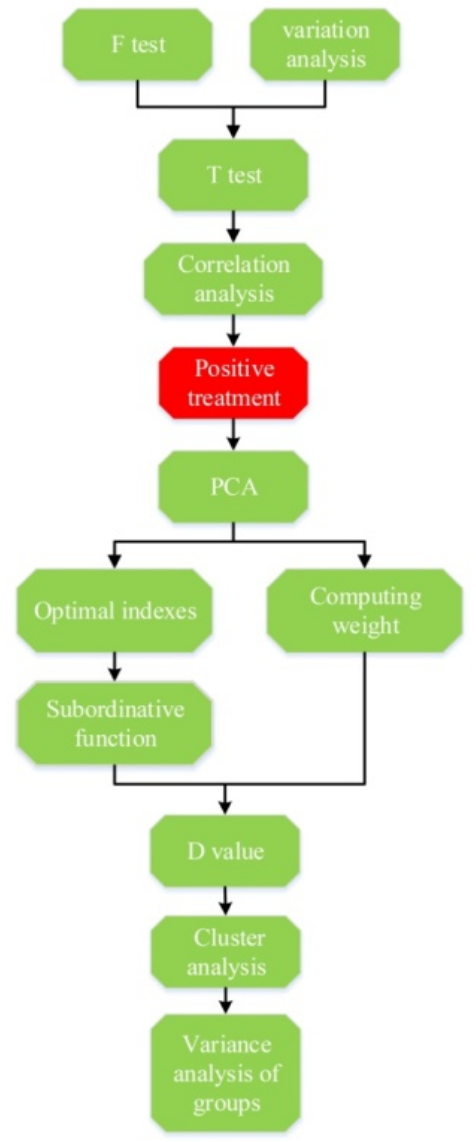

1

Fig. 9 The comparison of the comprehensive evaluation systems.

The module filled with red is the new step supplemented by the authors; the module filled with green is the parts of this new evaluation system and the dotted black line stands for the omitted steps in this new system. 
electrical conductivity and the score of PC3 increased with the increasing of electrical conductivity, which would produce error accumulation for score in the final $D$ value. This error appeared in many papers used for PCA. In this experiment, the indexes were not all in positive direction. So before PCA, carrying out the positive treatment in corresponding indexes was essential. Secondly, the comparison analysis between DR and NDR after PCA were made in this study. After PCA (DR), the workload was reduced, while in order to make sure whether reducing data could affect the evaluation results, the PCA (DR and NDR) was carried out. While the two methods almost got similar results by computing the side sameness $(S)$ [15] based on Pareto principle [16] between NDR and DR. The value of $S$ for $\operatorname{GSDV}_{(\mathrm{NDR})}$ and $\mathrm{GSDV}_{(\mathrm{DR})}$ was 1 , and the value of $S$ for $\operatorname{SSDV}_{(\mathrm{NDR})}$ and $\operatorname{SSDV}_{(\mathrm{DR})}$ was 0.917, which indicated that DR would not create greater deviation and DR reduced work load.

Because of the traditional method for evaluation was so fussy, the possibility of reducing operation steps were considering, and then the optimal index (OI) method was established (Fig. 9b). After PCA, the major factors were directly extracted and the weight based on corresponding PCs was computed. So, the standardized data did not need to record, and the component score coefficient and the final score of PCs did not need to compute too, which is the main computation for the old method. The results for the three methods (DR, NDR and OI) were compared by computing $S$. The value of $S$ for OI and DR or OI and NDR were all 0.833 . Furthermore, the final results for thermo-tolerance of tomato genotypes at different stages were got, and it was found that three methods were got extremely similar results (Table 3). Therefore, lesser steps and data could be adopted for comprehensive evaluation. At germination stage, GP could perfectly represent the other indexes, which was the most closed to $\mathrm{PC} 1$, while, as for seedling stage, it was FW (PC1), IL (PC2) and DMP (PC3). Based on the OI and its weight, the evaluation was got as Eq.
(12). It could predict thermo-tolerance of tomato. The verification experiment also exhibited its reliability in the evaluation of thermo-tolerance of tomato.

\subsection{Correlation of Thermo-Tolerance of Tomato at Different Development Stages}

Currently, the research about thermo-tolerance of plants mostly concentrated on seedling stage. While, combining with germination, seedling and flowering stage for comprehensive evaluation and analyzing the relationship of thermo-tolerance among the three stages were rarely reported. Wang [7] found that the thermo-tolerance of germination stage was significantly positive correlated with the thermo-tolerance of seedling stage and not significant correlated with the thermo-tolerance of flowering stage, but the thermo-tolerance of seedling stage was significantly positive correlated with the thermo-tolerance of flowering stage in tomato. In addition, Zhou et al. [23, 24] found that the heat stress sensitivity of tomato for vegetative stage maintained consistent with reproductive stage. However, due to the lack of the tomato genotypes, these results could not get much more accurate conclusion that illustrated the relationships between the three stages. In this paper, the authors used 30 tomato genotypes to study the correlations for the three stages (Fig. 1). In addition, $\mathrm{GSDV}_{(\mathrm{DR})}$ or GOID, $\mathrm{SSDV}_{(\mathrm{DR})}$ or SOID, and FSR were adopted as indicators to analyze the correlations for the three stages. The authors found that the seedling stage was significant positive correlated with flowering stage, and the germination stage was not significant correlated with the seedling stage and flowering stage. In addition, 10 tomato genotypes were randomly chosen from the 30 genotypes, and the same results were got for the correlation of the three stage. Thus, as for tomato, the thermo-tolerance at seedling stage could represent the thermo-tolerance at flowering stage. So comprehensive evaluation of thermo-tolerance of tomato only needs to evaluate germination and 
seedling stage or germination and flowering stage, which could further expedite the process of comprehensive evaluation.

\section{Conclusions}

In general, this study perfected the evaluation system of thermo-tolerance of tomato and provided a new reliable method not only for heat tolerance evaluation in tomato, but also for the stress evaluation in other plants. By correlation analysis, it was found that seedling stage showed significant positive correlation with flowering stage. Additionally, tomato genotypes with different heat tolerance ability at different stages achieved in this study, especially for tomato No. 26 with increased heat tolerances at whole developmental stages, can be used by cultivators and breeders for cultivating and the genetic improvement of heat tolerance, respectively.

\section{Acknowledgments}

This work was supported by grants from the Natural Science Foundation of Youth Jiangsu Province (BK20160579).

\section{References}

[1] Camejo, D., Rodríguez, P., Morales, M. A., Dell'Amico, J. M., Torrecillas, A., and Alarcón, J. J. 2005. "High Temperature Effects on Photosynthetic Activity of Two Tomato Cultivars with Different Heat Susceptibility." J. Plant Physiol. 162 (3): 281-9.

[2] Sato, S., Peet, M. M., and Thomas, J. F. 2000. "Physiological Factors Limit Fruit Set of Tomato (Lycopersicon esculentum Mill.) under Chronic, Mild Heat Stress." Plant, Cell and Environment 23 (7): 719-26.

[3] Zhang, J., Jiang, X. D., Li, T. L., and Cao, X. J. 2014. "Photosynthesis and Ultrastructure of Photosynthetic Apparatus in Tomato Leaves under Elevated Temperature." Photosynthetica 52 (3): 430-6.

[4] Molina-Bravo, R., Arellano, C., Sosinski, B. R., and Fernandez, G. E. 2011. "A Protocol to Assess Heat Tolerance in a Segregating Population of Raspberry Using Chlorophyll Fluorescence." Scientia Horticulturae 130 (3): 524-30.

[5] Wahid, A. S., Gelani, S., Ashraf, M., and Foolad, M. R. 2007. "Heat Tolerance in Plants: An Overview." Environ.
Exp. Bot. 61 (3): 199-223.

[6] Chen, L., Song, S., and Fu, J. 1998. "The Induction of High Temperature Tolerance during Germination of Tomato Seeds." Seed 48: 654-63. (in Chinese)

[7] Wang, D. 2005. "Studies on Method for Identification of Heat Tolerance of Tomato and Selection of Heat Tolerance Germplasm.” M.Sc. thesis, China Northeast Agricultural University. (in Chinese)

[8] Levy, A., Rabinowitch, H. D., and Kedar, N. 1978. "Morphological and Physiological Characters Affecting Flower Drop and Fruit Set of Tomatoes at High Temperatures." Euphytica 27 (1): 211-8.

[9] Abdalla, A., and Verderk, K. 1968. "Growth, Flowering and Fruit Set of the Tomato at High Temperature." Netherlands J. Agric. 16: 71-6.

[10] Cao, X., Jiang, F. L., Wang, X., Zang, Y. W., and Wu, Z. 2015. "Comprehensive Evaluation and Screening for Chilling-Tolerance in Tomato Lines at the Seedling Stage.” Euphytica 205 (2): 569-84.

[11] Miao, Y. M., Ning, Y., Cao, Y. J., Shen, J., Pang, X., Cui, L., Cheng, C. Y., and Chen, J. F. 2013. "Evaluation of Cucumber's Chilling Tolerance at Germination and Seedling Stages." Chinese J. Appl. Ecol. 24 (7): 1914-22. (in Chinese)

[12] Wang, S., Wang, Z., Ping, W., Wang, H., Fu, L. I., Wei, H., and Yuguo, W. U. 2011. "Evaluation of Wheat Freezing Resistance Based on the Responses of the Physiological Indices to Low Temperature Stress." Acta Ecol. Sin. 31: 1064-72.

[13] Wu, H., Hou, L. L., Zhou, Y. F., Fan, Z. C., Shi, J. Y., Aliyan, R., and Zhang, J. S. 2012. "Analysis and Evaluation Indicator Selection of Chilling Tolerance of Different Cotton Genotypes.” Agric. Sci. Tech. 13 (11): 2338-46.

[14] Hong, B., Ma, C., Yang, Y. J., Wang, T., Yamaguchi-Shinozaki, K., and Gao, J. P. 2009. "Over-Expression of AtDREB1A in Chrysanthemum Enhances Tolerance to Heat Stress." Plant Mol. Biol. 70 (3): 231-40.

[15] Yu, L., Pan, Y., and Wu, Y. 2008. "Two New Indicators to Compare Different Evaluation Methods' Effect_—_Based on Times Higher-QS World University Rankings." Journal of Nanjing Normal University 31 (3): 135-40.

[16] Woolhouse, M. E., Dye, C., Etard, J. F., Smith, T., Charlwood, J. D., Garnett, G. P., Hagan, P., Hii, J. L., Ndhlovu, P. D., Quinnell, R. J., Watts, C. H., Chandiwana, S. K., and Anderson, R. M. 1997. "Heterogeneities in the Transmission of Infectious Agents: Implications for the Design of Control Programs." Proc. Natl. Acad. Sci. USA 94 (1): 338-42.

[17] Ahuja, I., De Vos, R. C., Bones, A. M., and Hall, R. D. 
in Tomato at Different Growth Stage

2010. "Plant Molecular Stress Responses Face Climate Change." Trends in Plant Science 15 (12): 664-74.

[18] Lobell, D. B., Schlenker, W., and Costa-Roberts, J. 2011. "Climate Trends and Global Crop Production since 1980." Science 333 (6042): 616-20.

[19] Mittler, R. 2006. "Abiotic Stress: The Field Environment and Stress Combination." Trends in Plant Science 11 (1): 15-9.

[20] Tubiello, F. N., and Howden, S. M. 2007. "Crop and Pasture Response to Climate Change." Proc. Natl. Acad. Sci. USA 104 (50): 19686-90.

[21] Wheeler, T. R., Craufurd, P. Q., Ellis, R. H., Porter, J. R., and Prasad, P. V. V. 2000. "Temperature Variability and the Yield of Annual Crops." Agric. Ecosyst. Environ. 82:
159-67.

[22] Jolliffe, I. 2005. "Principal Component Analysis." In Encyclopedia of Statistics in Behavioral Science. Chichester: John Wiley \& Sons, Ltd..

[23] Zhou, R., Kjær, K. H., Rosenqvist, E., Yu, X. Q., Wu, Z., and Ottosen, C. O. 2016. "Physiological Response to Heat Stress during Seedling and Anthesis Stage in Tomato Genotypes Differing in Heat Tolerance." $J$. Agron. Crop Sci. 203 (1): 68-80.

[24] Zhou, R., Yu, X. Q., Kjær, K. H., Rosenqvist, E., Ottosen, C. O., and Wu, Z. 2015. "Screening and Validation of Tomato Genotypes under Heat Stress Using Fv/Fm to Reveal the Physiological Mechanism of Heat Tolerance." Environ. Exp. Bot. 118: 1-11. 